Alexandre Emidio Ribeiro Silva'

Ana Maria Baptista Menezes'

Flávio Fernando Demarco'

Fabiana Vargas-Ferreira'

Marco Aurélio Peres"

\section{Obesity and dental caries: systematic review}

\section{Obesidade e cárie dentária: revisão sistemática}

Programa de Pós-Graduação em Epidemiologia. Universidade Federal de Pelotas. Pelotas, RS, Brasil

\footnotetext{
Australian Research Centre for Population Oral Health. School of Dentistry. University of Adelaide. Adelaide, Australia
}

\section{Correspondence:}

Alexandre Emidio Ribeiro Silva Universidade Federal de Pelotas

Rua Marechal Deodoro, $11603^{\circ}$ piso

96020-220 Pelotas, Brasil

E-mail: emidio3@ig.com.brl

\begin{abstract}
OBJECTIVE: Identifying, through a systematic literature review, evidence of a possible association between obesity and dental caries.

METHODS: A search of articles published between 2005 and January 2012 was performed in the Medline/PubMed, LILACS and Web of Science databases. The quality of scientific evidence of the selected articles was assessed by the items proposed for observational studies in the Downs \& Black instrument.

RESULTS: Initially, 537 references were found; after checking the titles and abstracts by two independent researchers, twenty-eight articles were selected for complete reading. Ten of them that assessed the primary and/or permanent dentition observed a positive association between obesity and dental caries and one study found an inverse association. According to the Downs \& Black classification, thirteen articles with good scientific evidence were found.
\end{abstract}

CONCLUSIONS: The present review did not find sufficient evidence regarding the association between obesity and dental caries, and it did not clarify the possible role of diet and other possible effect modifiers on this association.

DESCRIPTORS: Dental Caries, Epidemiology. Obesity. Observational Studies. Review. 


\section{RESUMO}

OBJETIVO: Analisar evidências da associação entre obesidade e cárie dentária.

MÉTODOS: Foi realizada revisão sistemática de artigos indexados nas bases de dados Medline/PubMed, Web of Sciences e LILACS, no período entre 2005 e janeiro de 2012, para identificar associação existente entre obesidade e carie dentária. A qualidade da evidência cientifica dos artigos selecionados foi verificada pelos itens propostos para estudos observacionais do instrumento Downs \& Black.

RESULTADOS: Inicialmente foram encontradas 537 referências após a verificação dos títulos e resumos por dois pesquisadores independentes. Foram selecionados 27 artigos para leitura completa. Destes, dez avaliaram dentição decídua e/ou permanente e observaram uma associação positiva entre obesidade e cárie dentária, sendo que um estudo encontrou uma associação inversa. Segundo a classificação de Downs \& Black, treze artigos foram considerados com boa evidência científica.

CONCLUSÕES: A presente revisão não encontrou evidências suficientes quanto à associação entre obesidade e cárie, assim como não esclareceu o possível papel da dieta e de outros possíveis modificadores de efeito nessa associação.

DESCRITORES: Dental Caries, Epidemiology. Obesity. Observational Studies. Review.

\section{INTRODUCTION}

Overweight and obesity, defined as excess body fat compared to lean body mass, ${ }^{19}$ are a growing public-health problem in the world..$^{15}$ Decreasing physical activity, increasing sedentary lifestyles and dietary changes are factors strongly associated with the development of overweight and obesity. ${ }^{12}$ Studies have observed increases in being overweight in childhood and adolescence since the beginning of $2000,{ }^{21}$ resulting in the increased risk of cardiovascular diseases, respiratory disorders and other chronic diseases during adulthood. ${ }^{32}$

Diet plays an important role in the increased prevalence of obesity ${ }^{8}$ due to the higher consumption of foods rich in fat and carbohydrates. ${ }^{34}$ Overweight or obese children and adolescents reported higher consumption of sugary drinks and foods such as "fast food" compared with those who reported normal weight. ${ }^{34}$ Besides being directly associated with obesity, eating habits, especially regarding the intake of sucrose, have a well-established causal relationship with tooth decay, along with socio-demographic aspects, such as low socioeconomic status. ${ }^{27}$

A systematic review and meta-analysis ${ }^{7}$ published in 2010 identified a positive association between obesity and periodontal disease. However, the relationship between obesity and dental caries is unclear. Dental caries remains the most prevalent problem in oral health and it is associated with pain ${ }^{4}$ and a decrease in quality of life. ${ }^{16}$
Because caries is associated with poor dietary habits and inappropriate diets promote obesity, a biologically plausible association between obesity and dental caries has been inferred in the literature. ${ }^{14}$ However, the presence of a common factor such as a high-sugar diet, caused by the ingestion of food such as soft drinks, cake, and ice cream, seems to increase the probability of both diseases and seems to be the most acceptable theory to explain the relationship between obesity and dental caries. ${ }^{21}$ The biggest challenge in understanding this relationship is to measure the possible confounding variables (diet and income) and effect modifiers (age, oral hygiene habits and use of fluoridated water) in a standardized manner. ${ }^{32}$

A systematic review ${ }^{21}$ on the subject was indexed by Bireme, Medline, ISI (Thomson Scientific) and Cochrane Library in 2006, covering the age groups of childhood, adolescence, and adulthood. The exclusion criteria identified 33 articles for reading. At the end of the review, three cross-sectional studies, all performed with children, were identified as having good methodological quality. They presented conflicting results regarding the presence of a positive association between obesity and dental caries. Another systematic review and meta-analysis ${ }^{17}$ including studies published before 2010 indicated the presence of a positive association between obesity and dental caries in permanent dentition without clarifying the direction of this association. 
The present study deals with a systematic review in order to use the new evidence to update the literature between 2005 and January 2012 on the subject.

\section{METHODS}

A systematic review on obesity and dental caries was performed in the electronic databases of the Medline/ PubMed, LILACS, and the Web of Science, between 2005 and January 2012. This review included studies published after 2010, which were not included in the systematic review and meta-analysis published earlier on the subject, new scientific evidence to try to clarify the relationship between obesity and dental caries have been added to this study. The first search used the English terms "dental caries" and "obesity". These two terms are the same as those used in the systematic review performed on the same subject by Kantovitz \& Pascon; Rontani \& Gavião ${ }^{21}$ (2006) with articles published between 1984 and 2004. The following keywords were used for the definition of caries: "DMFT index", "tooth decay"; for the explanatory variable the keywords "waist circumference", "skinfolds" and "body mass index" were used. These descriptors were found in the articles selected in the first search conducted on the subject. For the combination of descriptors, the logical operators "AND” and "OR" were used.

The process of finding the scientific papers to write the review consisted of four steps. The first was the identification of titles in the databases PubMed, LILACS, and Web of Science. Exclusion criteria used in reading the titles consisted of: review articles, protocols on nutrition and food issues, studies on oral health and diet-specific items and obesity studies related to other oral diseases.

The second stage consisted of two researchers independently reading the eligible abstracts. The search also excluded those items that assessed participants aged six and under, articles published before 2004, articles evaluating specific populations such as schizophrenic patients, and master's dissertations or PhD theses. The few disagreements that occurred were discussed by the two researchers, who then reached a consensus.

The third stage consisted of reading the articles, applying the same exclusion criteria mentioned above.

In the fourth step, all the references of the selected articles were checked in order to find any study not found in the databases previously consulted by the authors.

The quality of the scientific evidence in the selected articles was assessed using the criteria of Downs \& Black $^{13}$ (1998). Of the 27 items proposed by the authors, 18 were selected. Those items evaluating intervention studies were excluded because none of the 28 articles selected for review had used this design. The items excluded from Downs \& Black's classification were:
Are the interventions of interest clearly described? Does the study provide estimates of the random variability in the data for the main outcomes? Have all important adverse events that may be a consequence of the intervention been reported? Were the staff, places, and facilities where the patients were treated, representative of the treatment the majority of patients receive? Was an attempt made to blind study subjects to the intervention they have received? Was an attempt made to blind those measuring the main outcomes of the intervention? Was compliance with the intervention/s reliable? Were study subjects randomized to intervention groups? and Was the randomized intervention assignment concealed from both patients and health care staff until recruitment was complete and irrevocable? The articles with ten or more items scored by both evaluators in the review were found to have good scientific evidence. The criteria to consider an article as producing good evidence were given by the study authors. The choice of a cut-off point of ten or more items is due to the fact that the Article evaluated as having good scientific evidence had to have more than $50 \%$ of the items from the Downs \& Black classification positively evaluated by two researchers of the study. For cases in which there was disagreement about the scores of articles between the two researchers, i.e., one researcher considered the article to have good scientific evidence and the other does not, a new assessment was performed and a consensus reached without the need for a third appraiser's evaluation.

\section{RESULTS}

Initially, 346 titles were identified in PubMed, 21 in LILACS, and 170 in Web of Science. After reading the titles, 81 were selected for reading the abstracts: 66 from PubMed, six from LILACS, and nine from Web of Science. Studies involving participants $<6$ years old were excluded after reading the articles. Twenty-eight articles published between 2005 and 2012 were identified. All the references were checked and six articles were found that did not meet the review's inclusion criteria (Figure).

Among the 28 articles, 25 were in English, two in Spanish and one was in Portuguese. Twenty-four studies had a cross-sectional design, three were prospective cohort and one was a case control (Tables 1 and 2); Table 1 lists all studies that did not perform adjusted statistical analysis, while those with adjusted statistical analysis are shown in Table 2.

The ages evaluated ranged from three to 20. Although one of the exclusion criteria was age $<6$ years, few studies have evaluated various age groups including children $<6$ years, and therefore, they were included in the review. For those studies that performed separate analyses by age groups, only groups with participants $>6$ years were included. 
The measure of obesity in the 28 studies was Body Mass Index (BMI), and BMI information was self-reported in two of these studies. ${ }^{9,10}$ The classification of BMI showed no uniformity. Nine studies used the International Obesity Task Force (IOTF) for age and sex and seven assessed BMI through percentiles developed in the United States to determine the population's standard weight (Center for Disease Control and Prevention - CDC 2000). Three studies used BMI for age and one used for age and weight. Finally, eight studies were also checked which had other methods for obtaining BMI.

Seventeen studies assessed decay through teeth or decayed, missing, or filled surfaces - DMFT or DMFS, or, by means of DMFT or DMFS, in case of the primary dentition. The dental caries were assessed by interproximal radiographs in two studies, through the teeth or decayed and filled surfaces in four, by means of decayed teeth and interproximal radiographs in one study, by decayed surfaces and interporximal radiographs in another study, and through surfaces or decayed teeth in two studies (Tables 1 and 2).

The positive association between obesity and dental caries in permanent teeth was identified in six studies, a negative association was found in one, and eight showed no association. For studies evaluating mixed dentition (deciduous and permanent), four of them found a positive association, one found positive correlation, and seven showed no association. There was no correlation between obesity and caries in a study in which permanent dentition was analyzed (Tables 1 and 2).

When considering studies for the presence of some type of analysis adjusted for other variables that could confound the association between obesity and dental caries, 15 articles described which variables performed the adjustment. ${ }^{5,8-10,15,19,22-24,27,29,33,36,40,41}$ Eight studies included adjustments for age and sex, 6,19,23,27,29,33,36,41 two only for sex, ${ }^{15,22}$ and five for consumption of any type of food, such as soft drinks, ${ }^{10,24}$ fruits or snacks between meals, ${ }^{10}$ "fast food", ${ }^{10}$ and milk, ${ }^{9}$ as well as daily sugar consumption ${ }^{19}$ and "snack" consumption more than three times a day. ${ }^{29}$

Among the 28 articles, 13 were considered to have good scientific evidence according to the criteria of Downs \& Black. Eight of them with adjusted analysis and five articles without adjusted analysis were considered to be of good scientific quality (Tables 1 and 2).

Of these 13 articles, six found a positive association, showing that individuals with higher BMI values had more caries, and there was no association between obesity and dental caries in the other seven studies (Tables 1 and 2).

\section{DISCUSSION}

Between 2005 and 2012, 28 eligible articles which analyzed the relationship between obesity and dental caries were found. After applying the exclusion criteria for the revision and those proposed by Downs \& Black, ${ }^{13}$ thirteen studies were shown to have good scientific evidence. However, they did not shed light on the link between obesity and dental caries.

Unlike the systematic review by Kantovitz \& Pascon; Rontani \& Gavião ${ }^{21}$ (2006), this review excluded studies on individuals $<6$ years old, as it has been observed that the use of cariogenic foods have a greater impact on the appearance of dental caries increasing the likelihood of association between obesity and caries, after the age of six. ${ }^{39}$ Moreover, in early childhood there is greater parental control over food intake and oral hygiene practices, which can mean lower prevalence of both diseases. ${ }^{39}$ The opposite is also true. Parents that do not perform preventive oral health behaviors and food control, especially regarding the sugar consumption, increase the chances of caries in the primary dentition, and later in the permanent dentition, concomitantly with the presence of obesity. ${ }^{5}$

Studies that evaluated the association between dental caries and obesity indicate a variety of factors to be discussed in order to understand this relationship. The first issue refers to methods for the diagnosis of both diseases. The main diagnostic method for caries is the visual examination of the teeth or surfaces, and this method was used in most studies. However, this diagnostic method can often lead to lower levels of detection of the disease. Some studies using this method considered only the decayed teeth, not those restored or extracted due to caries. ${ }^{6}$ Other studies ${ }^{1,2}$ used interproximal radiographs, a method more sensitive to caries diagnosis. Using this method is likely to identify higher prevalence of the disease by detecting caries at earlier stages of cavitation. Using this type of examination for diagnosis in epidemiological surveys is not suitable because it is an expensive method and is primarily used by exposing the study population to examination when there is no clinical indication of disease.

There are also aspects that can interfere with measuring obesity. All studies included in this review measured obesity by BMI. There was no study measuring obesity using other diagnostic methods such as skinfold thickness, waist circumference, waist/hip ratio, or x-ray densitometry (DXA), all of which are more accurate methods for identifying levels of obesity. The probable explanation for this is the ease of implementation, objectivity, and comparability with a BMI reference standard, especially in population studies. ${ }^{14}$ The limitation of this index, which does not differentiate between lean body mass and fat mass and therefore often produces false positive results, must be considered 


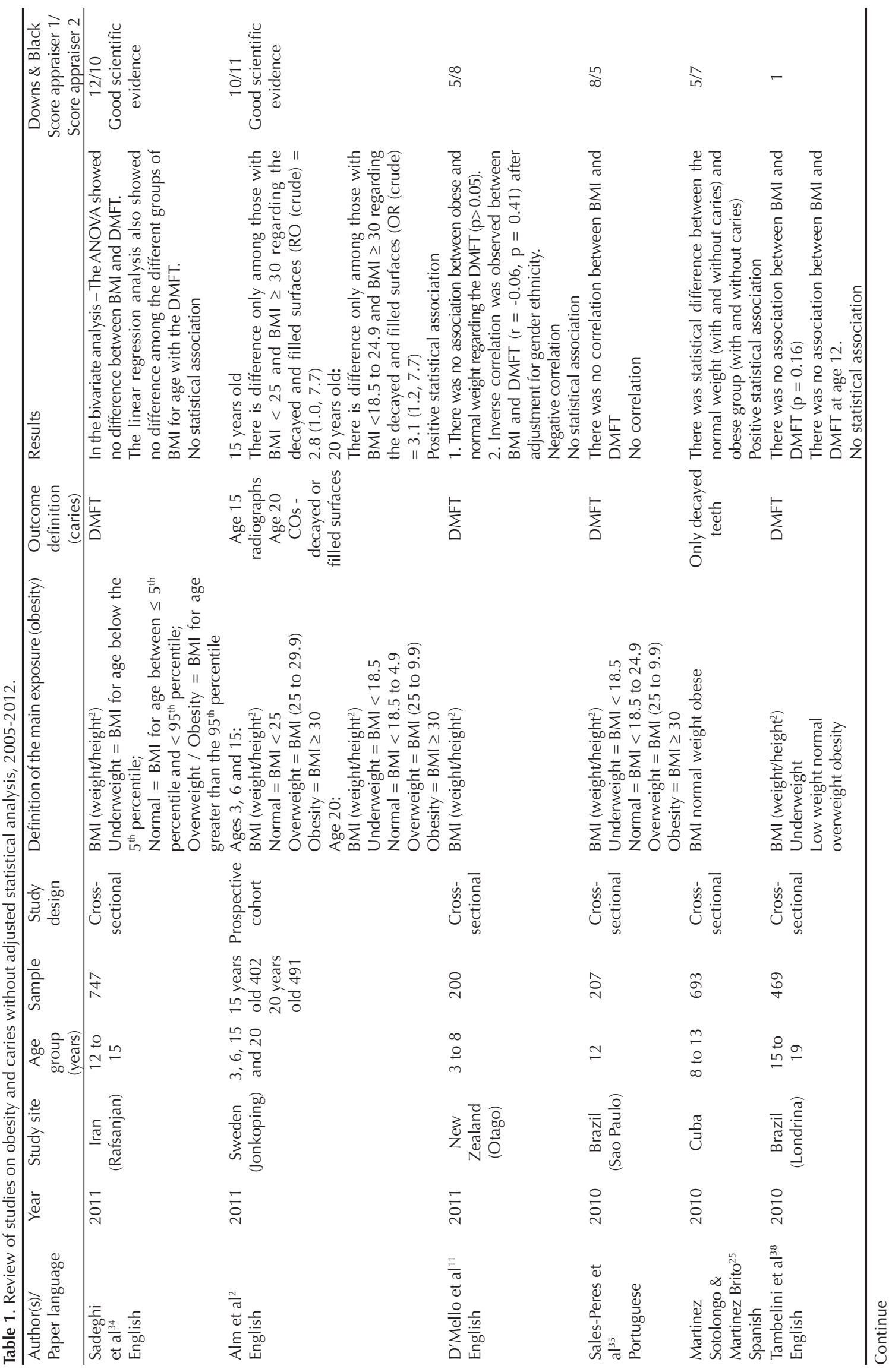




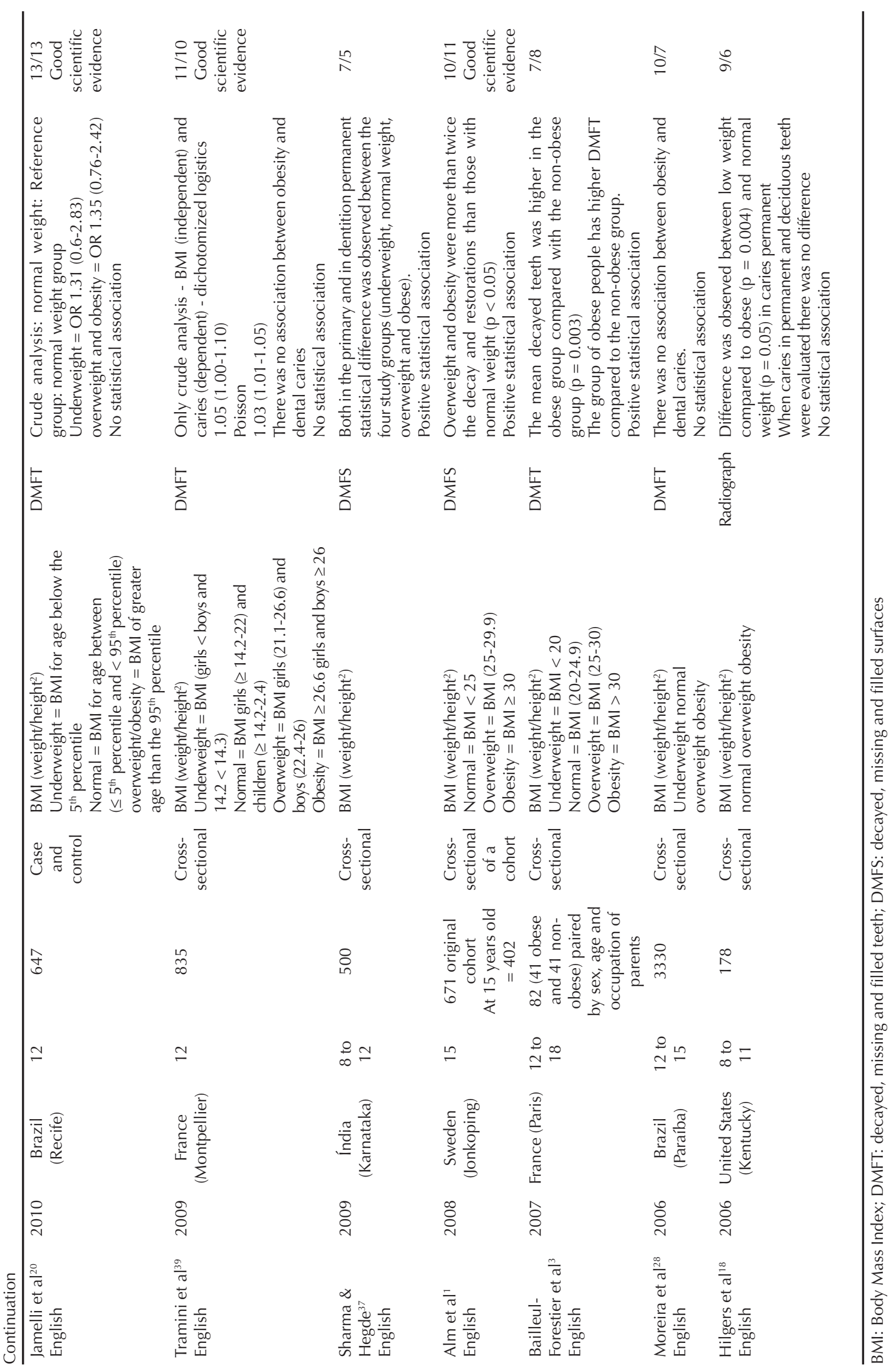


prior to the study. The non-use of DXA as a more appropriate method to measure obesity is probably due to the examination cost, which often makes it impossible to use in population studies.

A second point refers to the population's access to oral health services and the use of fluorinated substances. These two factors are considered as potential effect modifiers that may lead to a weak or negative association between obesity and caries. ${ }^{19}$ However, these factors were treated as potential confounders in studies in this review. In the present work, most studies showing an association were performed in European countries where oral health services are organized and available to the public, in addition to various forms of administering fluorinated substances being made available. The lack of association between obesity and dental caries was identified mainly in Latin American countries. Four of these studies were conducted in Brazil at the following locations: Bauru, ${ }^{35}$ Southeastern Brazil, with 6.8 to $8.5 \%$ of adolescents studied presenting overweight and obesity; in cities belonging to the state of Paraíba, Northeastern Brazil, ${ }^{28}$ with 30\% participants aged between 12 and 15 obese; in Londrina, ${ }^{38}$ Southern Brazil, with 22.4\% of the adolescents aged between 15 and 19 being overweight and obese; and in the city of Recife, Northeastern Brazil, ${ }^{20}$ with $12.5 \%$ of adolescents aged 12 with overweight and obesity. Some of these cities have used a fluoridated water supply for over 30 years, even though dental services are still not adequately structured to meet

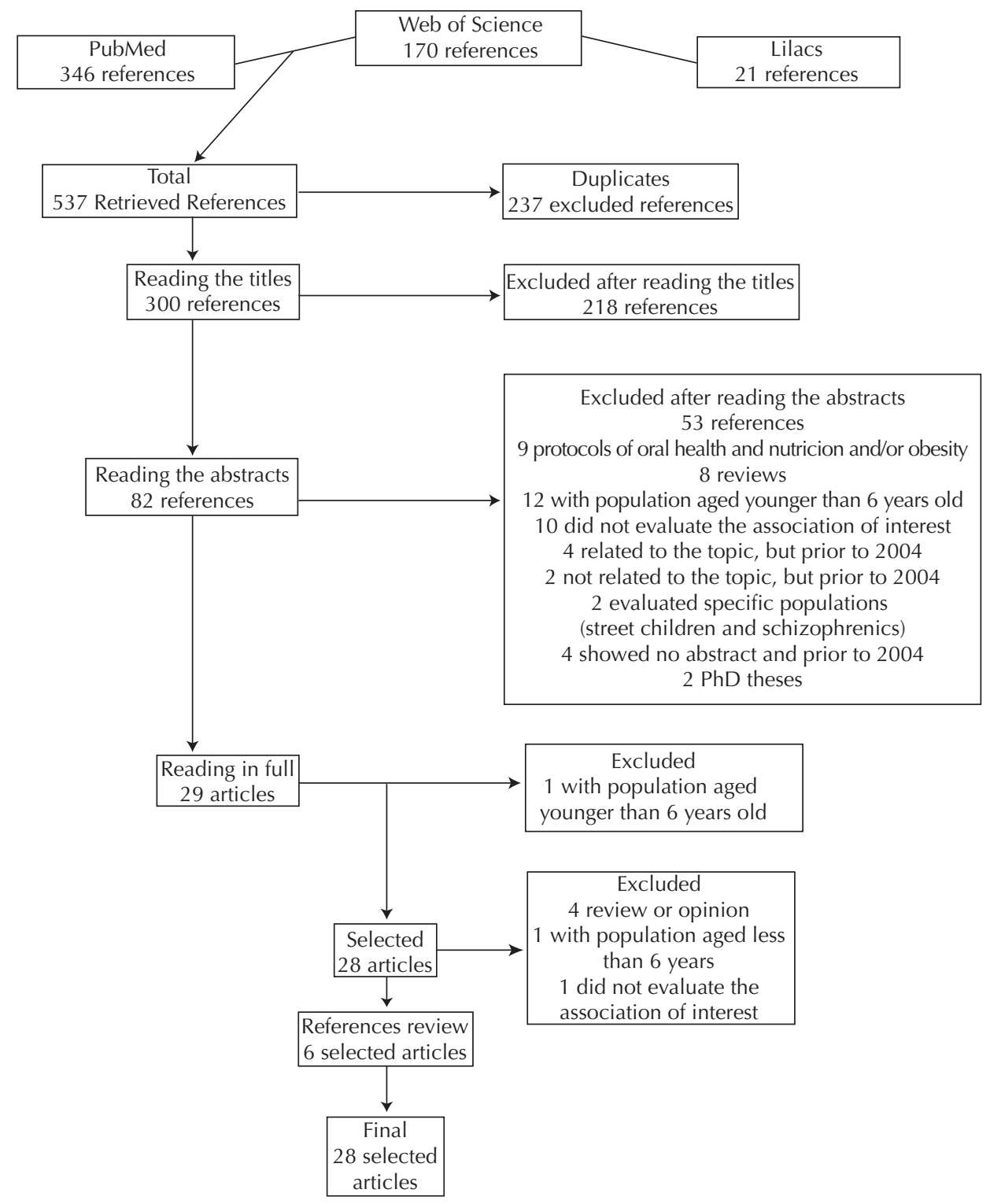

Figure. Search for scientific articles for the systematic review on obesity and dental caries, 2005-2012. 


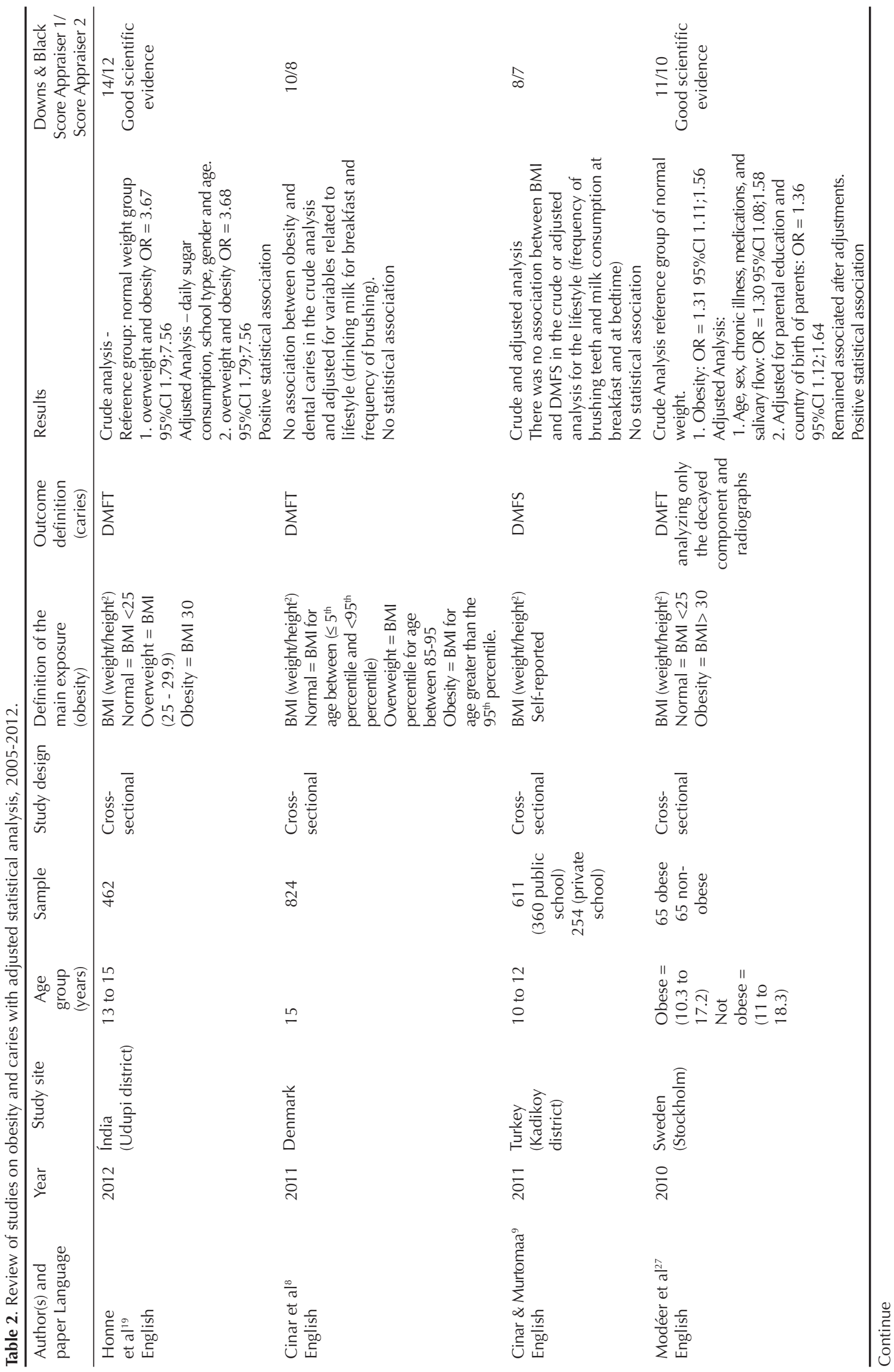




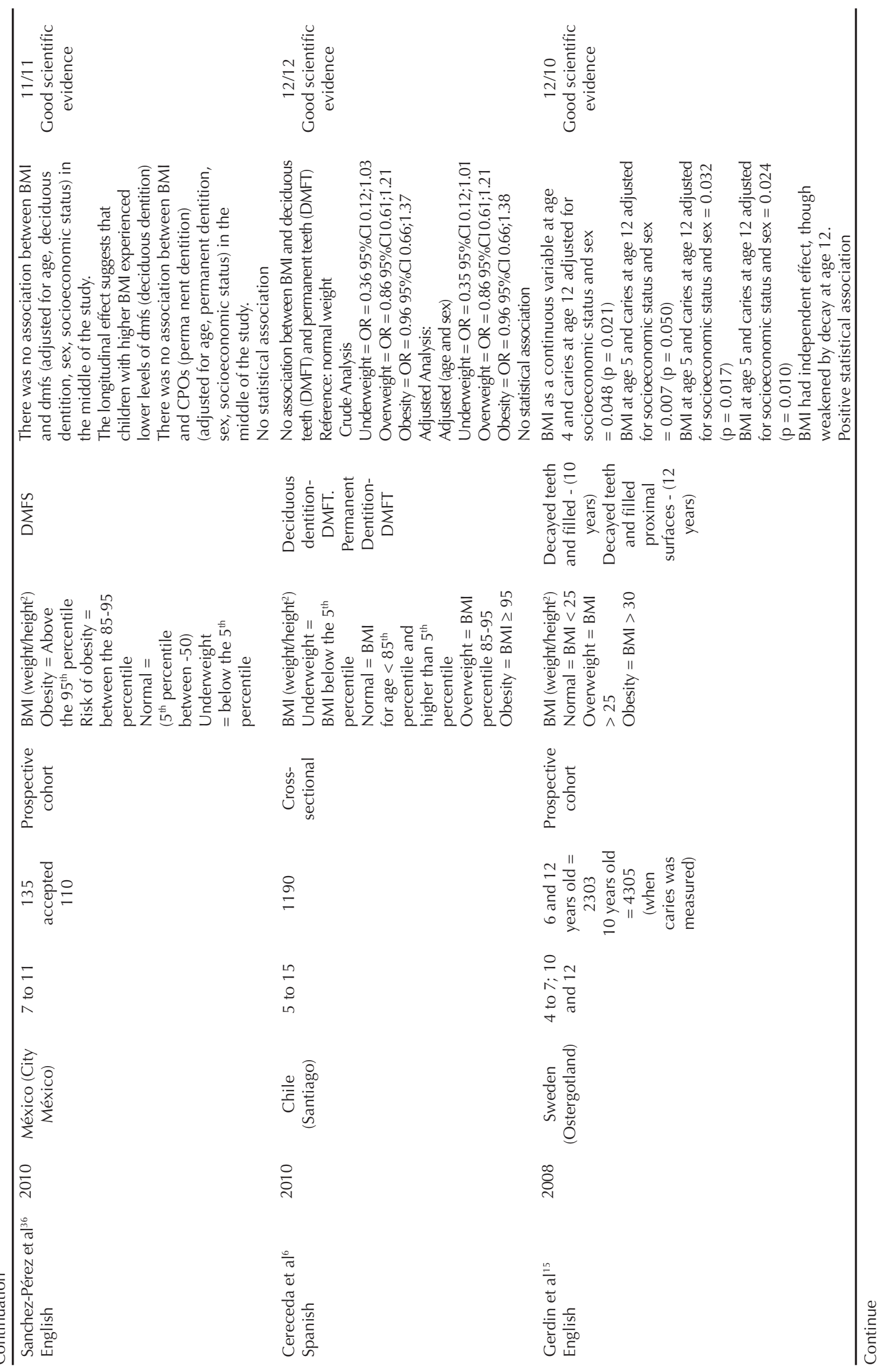




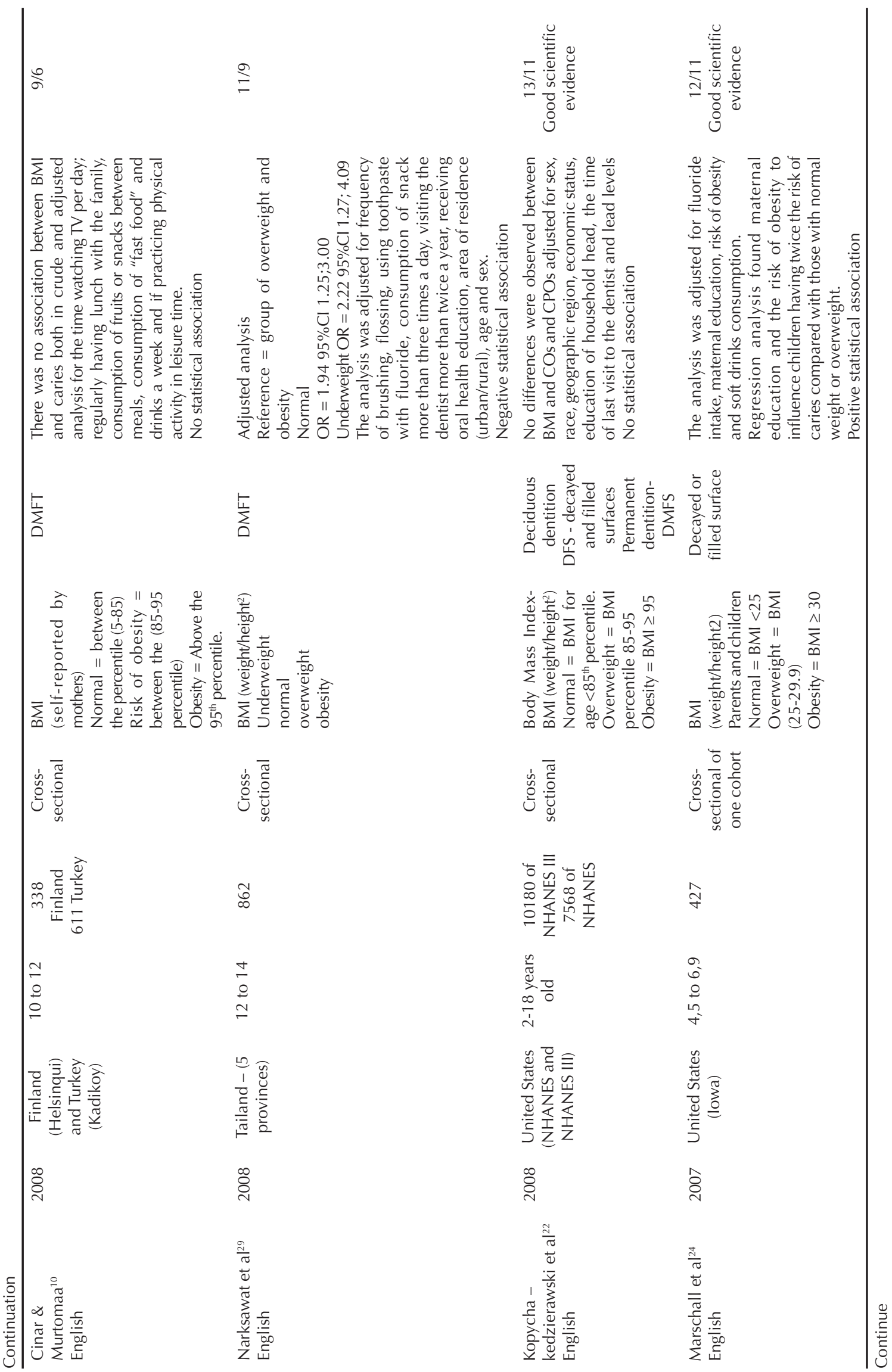




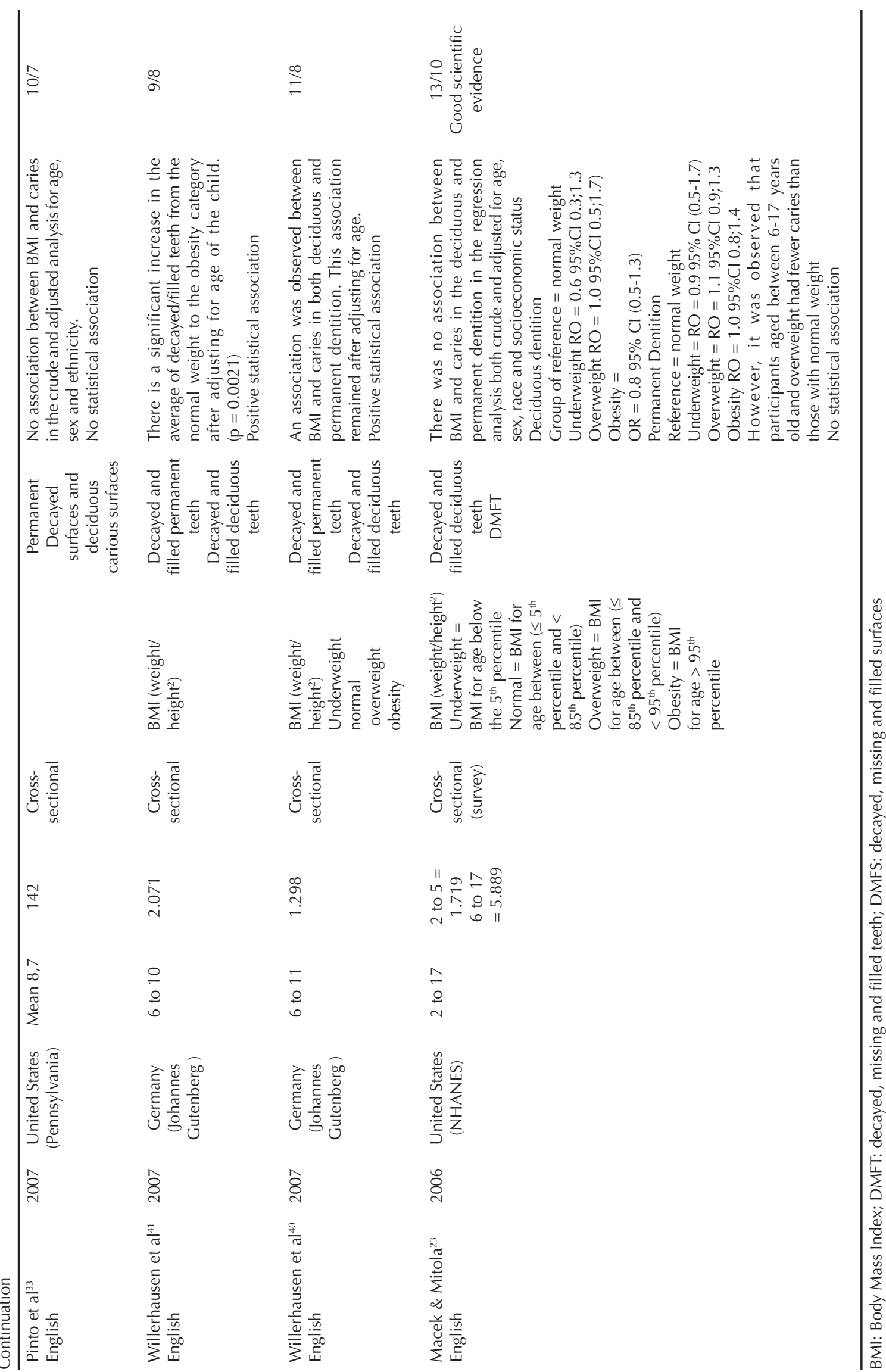


most of the population's needs. The lack of association in studies conducted in Latin America probably addresses socioeconomic and dietary conditions, different factors in countries of these two continents. Dietary habits and income ${ }^{20}$ are considered important factors for both dental caries and obesity. Dietary habits related to obesity and low incomes may provide a higher quantity and frequency of sucrose intake, which are important factors in caries etiology. ${ }^{35}$ Higher fat intake and decreased fiber may be associated with increased prevalence of caries and overweight/obesity among individuals with lower socioeconomic conditions. ${ }^{3}$ However, other authors reported that excessive consumption of fatty foods has less influence on the development of caries than diets rich in sugar, which could be somewhat responsible for the lack of association between obesity and the presence of caries observed in some studies. ${ }^{39}$

This review presents some limitations. A small number of studies (five) analyzed longitudinal data. When considering only those studies with good scientific evidence according to the criteria of Downs \& Black ${ }^{13}$ (1998), four used longitudinal data. The use of longitudinal data including information on various points of time is important because obesity in early life often leads individuals to change their habits to reduce body weight, resulting in a change in BMI scores. However, the scores for caries by means of DMF can remain high because this index considers caries throughout the individuals' lives. ${ }^{39}$ Moreover, children identified by parents as obese may be guided to restrict their sugar intake; however, if there is still a high consumption of fats and if their caloric intake is greater than expenditure, they will become overweight. ${ }^{36}$

The second limitation is the lack of adjustment in several studies for variables such as diet and socioeconomics. These two factors have been cited as associated with both diseases, and they should be considered in studies that aim to explain the relationship between obesity and dental caries. However, of the 28 articles examined, five had some kind of adjustment for diet, and four adjusted for socioeconomic issues.
A third limitation involves using the Downs \& Black instrument ${ }^{13}$ (1998) to evaluate the quality of scientific evidence from the studies. This instrument was originally developed to evaluate intervention studies, but it has been used for studies with other designs, excluding some of their items. ${ }^{26,30,31}$ Despite this limitation, it was considered useful for the present review because of its ideas about article quality.

It was not possible to perform a meta-analysis. First, due to the heterogeneity of the studies, particularly the methods used to obtain exposure - obesity of this review, and according to non-submission of primary data by most authors of the articles considered as good scientific evidence. A meta-analysis would help clarify the relationship between obesity and dental caries.

This review identified six studies with good scientific evidence, which observed a positive association between obesity and dental caries in children and adolescents, in contrast to what was described in the review by Kantovitz \& Pascon; Rontani \& Gavião ${ }^{21}$ (2006). They noted three studies with good scientific evidence, and of these one with positive association in children. Although this review found six studies with a positive association between obesity and dental caries, the causal mechanism remains unclear. It is unknown if the associations actually occurred because there is a direct relationship between obesity and dental caries or if diet, a factor common to both diseases, is responsible for this association. None of the studies was designed to consider all the possible effect modifiers (access to health services, use of fluorides, and oral health habits) and confusion factors (diet and income) from the literature. These results were similar to the recent systematic review and meta-analysis, ${ }^{17}$ although the present study had included articles from the literature published between 2011 and 2012. Thus, the studies identified in the literature provide clues about this relationship and indicate the need for new and more clearly delineated studies. 


\section{REFERENCES}

1. Alm A, Fahraeus C, Wendt LK, Koch G, AnderssonGare B, Birkhed D. Body adiposity status in teenagers and snacking habits in early childhood in relation to approximal caries at 15 years of age. Int J Paediatr Dent. 2008;18(3):189-96. DOI:10.1111/j.1365-263X.2007.00906.x

2. Alm A, Isaksson H, Fahraeus C, Koch G, AnderssonGare B, Nilsson M, et al. BMI Status in swedish children and young adults in relation caries prevalence. Swed Dent J. 2011;35(1):1-8.

3. Bailleul-Forestier I, Lopes K, Souames M, Azoguy-Levy S, Frelut ML, Boy-Lefevre ML. Caries experience in a severely obese adolescent population. Int J Paediatr Dent. 2007;17(5):358-63. DOI:10.1111/j.1365-263X.2007.00848.x

4. Boeira GF, Correa MB, Peres KG, Peres MA, Santos IS, Matijasevich A, et al. Caries is the main cause for dental pain in childhood: findings from a birth cohort. Caries Res. 2012;46(5):488-95 DOI:10.1159/000339491

5. Brandão IMG, Arcieri, RM, Sundefeld MLM, Moimaz SAS. Cárie precoce: influência de variáveis sóciocomportamentais e do lócus de controle de saúde em um grupo de crianças de Araraquara, São Paulo, Brasil. Cad Saude Publica. 2006;22(6):1247-56. DOI:10.1590/S0102-311X2006000600014

6. Cereceda MA, Faleiros S, Ormeño A, Pinto M, Tapia R, Díaz C, et al. Prevalencia de caries en alumnos de educación básica y su asociación con el estado nutricional. Rev Chil Pediatr. 2010;81(1):28-36. DOI:10.4067/S0370-41062010000100004

7. Chaffee BW, Weston SJ. Association between chronic periodontal disease and obesity: a systematic review and meta-analysis. J Periodontol. 2010; 81(12):1708-24. DOI:10.1902/jop.2010.100321

8. Cinar AB, Christensen IB, Hede B. Clustering of obesity and dental caries with lifestyle factors among Danish adolescents. Oral Health Prev Dent. 2011;9(2):123-130.

9. Cinar $A B$, Murtomaa $\mathrm{H}$. Interrelation between obesity, oral health and life-style factors among Turkish school children. Clin Oral Investig. 2011;15(2):177-84. DOI:10.1007/s00784-009-0368-z

10. Cinar B, Murtomaa H. Clustering of obesity and dental health with lifestyle factors among Turkish and Finnish pre-adolescents. Obes Facts. 2008;1(4):196-202. DOI:10.1159/000145931

11. D'mello G, Chia L, Hamilton SD, Thomson WM, Drummon BK. Childhood obesity and dental caries among paediatric dental clinic attenders. Int J Paediatr Dent. 2011;21(3):217-22. DOI:10.1111/j.1365-263X.2011.01112.x

12. Dietz WH. The obesity epidemic in young children. Reduce television viewing and promote playing. BMJ. 2001; 322(7282):313-4. DOI:10.1136/bmj.322.7282.313

13. Downs $\mathrm{SH}$, Black N. The feasibility of creating a checklist for the assessment of the methodological quality both of randomised and non-randomised studies of health care interventions. J Epidemiol
Community Health. 1998;52(6):377-84. DOI:10.1136/jech.52.6.377

14. Dye BA, Shenkin JD, Ogden CL, Marshall TA, Levy SM, Kanellis MJ. The relationship between healthful eating practices and dental caries in children aged 2-5 years in the United States, 1988-1994. I Am Dent Assoc. 2004;135(1):55-66.

15. Gerdin EW, Angbratt M, Aronsson K, Eriksson E, Johansson I. Dental caries and body mass index by socio-economic status in Swedish children. Community Dent Oral Epidemiol. 2008;36(5):459-65. DOI:10.1111/j.1600-0528.2007.00421.x

16. Goettems ML, Ardenghi TM, Romano AR, Demarco $\mathrm{FF}$, Torriani DD. Influence of maternal dental anxiety on the child's dental caries experience. Caries Res. 2012;46(1):3-8. DOI:10.1159/000334645

17. Hayden C, Bowler JO, Chambers S, Freeman R, Humphris G, Richards D, et al. Obesity and dental caries in children: a systematic review and metaanalysis. Community Dent Oral Epidemiol 2012;41(4):289-308 DOI:10.1111/cdoe.12014

18. Hilgers KK, Kinane DE, Scheetz JP. Association between childhood obesity and smooth-surface caries in posterior teeth: a preliminary study. Pediatr Dent. 2006;28(1):23-8.

19. Honne T, Pentapati K, Kumar N, Acharya S. Relationship between obesity/overweight status, sugar consumption and dental caries among adolescents in South India. Int J Dent Hyg. 2012;10(4):240-4. DOI:10.1111/j.1601-5037.2011.00534.x

20. Jamelli SR, Rodrigues CS, Lira PI. Nutritional status and prevalence of dental caries among 12-year-old children at public schools: a case-control study. Oral Health Prev Dent. 2010;8(1):77-84.

21. Kantovitz KR, Pascon FM, Rontani RMP, Gavião MBD. Obesity and dental caries - a systematic review. Health Prev Dent. 2006;4(2):137-44.

22. Kopycka-Kedzierawski DT, Auinger P, Billings RJ, Weitzman M. Caries status and overweight in 2- to 18-year-old US children: findings from national surveys. Community Dent Oral Epidemiol. 2008;36(2):157-67. DOI:10.1111/j.1600-0528.2007.00384.x

23. Macek MD, Mitola DJ. Exploring the association between overweight and dental caries among US children. Pediatr Dent. 2006;28(4):375-80.

24. Marshall TA, Eichenberger-Gilmore JM, Broffitt BA, Warren JJ, Levy SM. Dental caries and childhood obesity: roles of diet and socioeconomic status. Community Dent Oral Epidemiol. 2007;35(6):449-58. DOI:10.1111/j.1600-0528.2006.00353.x

25. Martínez Sotolongo B, Martínez Brito I. Comportamiento de la caries dental en escolares obesos y normopesos de 8 a 13 años. Rev Medica Electron. 2010;32(3).

26. Martins EB; Carvalho MS. Associação entre peso ao nascer e o excesso de peso na infância: revisão sistemática. Cad. Saude Publica. 2006;22(11):2281-300. DOI:10.1590/S0102-311X2006001100003 
27. Modéer T, Blomberg CC, Wondimu B, Julihn, Marcus C. Association between obesity, flow rate of whole saliva, and dental caries in adolescents. Obesity (Silver Spring). 2010;18(12):2367-73. DOI:10.1038/oby.2010.63

28. Moreira PV, Rosenblatt A, Severo AM. Prevalence of dental caries in obese and normal-weight Brazilian adolescents attending state and private schools. Community Dent Health. 2006;23(4):251-3.

29. Narksawat K, Tonmukayakul U, Boonthum A. Association between nutritional status and Dental caries in permanent dentition among Primary schoolchildren aged 12-14 years, Thailand. Southeast Asian J Trop Med Public Health. 2008;40(2):338-44.

30. Noal RB, Menezes AMB, Macedo SEC, Dumith SC. Childhood body mass index and risk of asthma in adolescence: a systematic review. Obes Rev. 2011;12(2):93-104. DOI:10.1111/j.1467-789X.2010.00741.x

31. Pacheco AHRN, Barreiros NSP, Santos IS, Kac G. Consumo de cafeína entre gestantes e prevalência do baixo peso ao nascer e da prematuridade: uma revisão sistemática. Cad Saude Publica. 2007;23(12):2807-19. DOI:10.1590/S0102-311X2007001200002

32. Perichart-Perera O, Balas-Nakash M, SchiffmanSelechnik E, Barbato-Dosal A, Vadillo-Ortega F. Obesity increases metabolic syndrome risk factors in school-aged children from an urban school in Mexico City. J Am Diet Assoc. 2007;107(1):81-91. DOI:10.1016/j.jada.2006.10.011

33. Pinto A, Kim S, Wadenya R, Rosenberg H. Is there an association between weight and dental caries among pediatric patients in an urban dental school? A correlation study. J Dent Educ. 2007;71(11):1135-40.

34. Sadeghi M, Lynch CD, Arsalan A. Is there a correlation between dental caries and body mass índex for age among adolescents in Iran? Community Dental Health. 2011;28(2):174-7.

35. Sales-Peres SH, Goya S, Sant'Anna RM, Silva HM, Sales-Peres C, Silva RP, et al. Prevalência de sobrepeso e obesidade e fatores associados em adolescentes na região centro-oeste do estado de São Paulo (SP, Brasil). Cienc Saude Coletiva. 2010;15 Suppl 2:3175-84. DOI:10.1590/S1413-81232010000800022

36. Sánchez-Pérez L, Irigoyen, Zepeda M. Dental caries, tooth eruption timing and obesity: a longitudinal study in a group of Mexican schoolchildren. Acta Odontol Scand. 2010;68(1):57-64. DOI:10.3109/00016350903449367

37. Sharma A, Hegde AM. Relationship between body mass index, caries experience and dietary preferences in children. J Clin Pediatr Dent. 2009; 34(1):49-52.

38. Tambelini CA, Ramos DM, Poli-Frederico RC, Tomasetti, CSC, Barata, TJE, Maciel SM. Dental caries in adolescents and its association with excess weight and sociodemographic factors in Londrina, Paraná, Brazil. Rev Odonto Cienc. 2010;25(3):245-9.

39. Tramini P, Molinari N, Tentscher M, Demattei C, Schulte AG. Association between caries experience and body mass index in 12-year-old French children. Caries Res. 2009;43(6):468-73. DOI:10.1159/000264684

40. Willerhausen B, Blettner M, Kasaj A, Hohenfellner K. Association between body mass index and dental health in 1,290 children of elementary schools in a German city. Clin Oral Investig. 2007;11(3):195-200. DOI:10.1007/s00784-007-0103-6

41. Willershausen B, Moschos D, Azrak B, Blettner M. Correlation between oral health and body mass index (BMI) in 2071 primary school pupils. Eur J Med Res. 2007;12(7):295-9.

The authors declare that there are no conflicts of interests. 